\title{
Noncommunicable disease, clinical course and COVID-19 prognosis: results based on I-CORE Registry
}

Shaghayegh Javanmard, ${ }^{1}$ Noushin Mohammadifard, ${ }^{2}$ Maryam Nasirian, ${ }^{3}$ Golnaz Vaseghi, ${ }^{4}$ Kamal Heidari, ${ }^{5}$ Behrouz Kelidari, ${ }^{6}$ Tahereh Changiz ${ }^{7}$ and Nizal Sarrafzadegan ${ }^{4,8}$

${ }^{1}$ Applied Physiology Research Center, Isfahan Cardiovascular Research Institute, Isfahan University of Medical Sciences, Isfahan, Islamic Republic of Iran. ${ }^{2}$ Hypertension Research Center, Cardiovascular Research Institute, Isfahan University of Medical Sciences, Isfahan, Islamic Republic of Iran. ${ }^{3}$ Infectious Diseases and Tropical Medicine Research Center; and Department of Epidemiology and Biostatistics, Health School, Isfahan University of Medical Sciences, Isfahan, Islamic Republic of Iran. ${ }^{4}$ Isfahan Cardiovascular Research Center, Cardiovascular Research Institute, Isfahan University of Medical Sciences, Isfahan, Islamic Republic of Iran (Correspondence to: N. Sarrafzadegan: nsarrafzadegan@gmail.com). ${ }^{5}$ Social Determinants of Health Research Center, Isfahan University of Medical Sciences, Isfahan, Islamic Republic of Iran. ${ }^{6}$ Department of Surgery, Isfahan Minimally Invasive Surgery and Obesity Research Center, Alzahra Hospital, Isfahan University of Medical Sciences, Isfahan, Islamic Republic of Iran. ${ }^{7}$ Department of Medical Education, Medical Educational Research Center, Isfahan University of Medical Science, Isfahan, Islamic Republic of Iran. ${ }^{8}$ School of Population and Public Health, Faculty of Medicine, University of British Columbia, Vancouver, Canada.

\begin{abstract}
Background: There are no data on the association between clinical course and comorbidity in Iranian patients with COVID-19.

Aims: To determine noncommunicable disease (NCD), clinical characteristics and prognosis of patients hospitalized with COVID-19 in Isfahan, Islamic Republic of Iran.

Methods: This multicentric retrospective observational study was performed on all patients hospitalized with COVID-19 in Isfahan from 17 February to 6 April 2020. We recruited 5055 patients. Data on clinical course and comorbid NCDs such as hypertension, coronary heart disease (CHD), diabetes mellitus (DM), cancer, chronic kidney disease (CKD) and chronic respiratory disease (CRD) were collected. Statistical analyses were done by Mann-Whitney U, $\chi^{2}$ and logistic regression tests using Stata version 14.

Results: DM and hypertension were the most prevalent comorbidities in patients with positive and negative reverse transcription polymerase chain reaction (RT-PCR). Odds ratio ( $95 \%$ confidence interval) of mortality-associated factors was significant for DM [1.35 (1.07-1.70)], CHD [1.58 (1.26-1.96)], CRD [2.18 (1.58-3.0)], and cancer [3.55 (2.42-5.21)]. These results remained significant for cancer after adjustment for age, sex and clinical factors. Among patients with positive RT-PCR, death was significantly associated with CRD and cancer, while this association disappeared after adjustment for all potential confounders. There was a significant association between NCDs and higher occurrence of low oxygen saturation, mechanical ventilation requirement and intensive care unit admission after adjustment for age and sex.
\end{abstract}

Conclusion: The presence of NCDs alone did not increase mortality in patients with COVID-19, after adjustment for all potential confounders including clinical factors.

Keywords : COVID-19, noncommunicable disease, mortality, cardiovascular disease, kidney disease

Citation: Javanmard S; Mohammadifard N; Nasirian M; Vaseghi G; Heidari K; Kelidari B et al. Noncommunicable disease, clinical course and COVID-19 prognosis: results based on I-CORE Registry. East Mediterr Health J. 2021;27(11):1036-1044. https://doi.org/10.26719/emhj.21.052

Received: 19/11/20; accepted: 06/04/21

Copyright (C) World Health Organization (WHO) 2021. Open Access. Some rights reserved. This work is available under the CC BY-NC-SA 3.0 IGO license (https://creativecommons.org/licenses/by-nc-sa/3.o/igo)

\section{Introduction}

In November 2019, the first cases of an epidemic of COVID-19 were detected in Wuhan, China, and it spread rapidly around the world (1). It has been acknowledged as a major international public health crisis, leading to a major global economic burden (2). According to the World Health Organization (WHO) announcement, the COVID-19 outbreak became a pandemic on 11 March 2020 (3). Up to 29 April 2020, this novel virus involved 210 countries and its territories with $>3100000$ confirmed cases and 218000 deaths worldwide (4). On 19 February 2020, the Islamic Republic of Iran reported its first cases of COVID-19 (5) and until 29 April 2020, it ranked eighth in the world for number of cases $(n=92584)$ and had the seventh highest death toll $(n=5877)(4)$.
Over $50 \%$ of the global burden of disease (6) and $70 \%$ of deaths have been attributed to the epidemic of noncommunicable diseases (NCDs) worldwide (7). In the Islamic Republic of Iran, NCDs account for $79 \%$ of all deaths and $74 \%$ of the disease burden (8). The COVID-19 pandemic has affected all aspects of life and health services worldwide. Initial case series have shown that people with NCDs are more likely to have critical disease when infected with the novel coronavirus $(9,10)$. Some measures for reducing the spread of COVID-19, including lockdowns, quarantine, social distancing, and travel limitations, could lead to restriction of physical activity, unavailability of healthy food, limited access to health services and postponement of routine medical examinations; all of which could interrupt NCD care. 
Additionally, the economic crisis due to the pandemic can increase stressful conditions and worsen NCD status (11).

In February 2020, Isfahan COVID-19 Registry (I-CORE) was established to register all patients hospitalized with COVID-19 in Isfahan (12). The catchment area included Isfahan Province except Kashan. According to WHO interim guidance for global surveillance (1), all confirmed and probable cases of COVID-19 that were hospitalized in Isfahan University of Medical Sciences (IUMS) affiliated hospitals were recruited in this registry.

This paper presents the clinical course and comorbidities such as hypertension, coronary heart disease (CHD), diabetes mellitus (DM), cancer, chronic kidney disease (CKD) and chronic respiratory disease (CRD), in patients hospitalized with COVID-19, and the impact of NCDs on outcomes of COVID-19.

\section{Methods}

\section{Design and participants}

This multicentre retrospective observational study was performed on all registered patients in I-CORE who were hospitalized in IUMS affiliated hospitals from 17 February to 6 April 2020. Isfahan is the second largest province in the Islamic Republic of Iran, with a population of850 1205 based on the national census in 2016. All patients who were hospitalized because of possible diagnosis of COVID-19 based on WHO criteria were recruited to this study, irrespective of their prognosis or real-time reverse transcription polymerase chain reaction (RT-PCR) results. COVID-19 was diagnosed according to WHO classification and consisted of having severe or moderate symptoms such as respiratory rate $>30$ breaths/minute, oxygen saturation $<94 \%$ in room air at sea level, ratio of arterial partial pressure of oxygen to fraction of inspired oxygen $\left(\mathrm{PaO}_{2} / \mathrm{FiO}_{2}\right)<300 \mathrm{mmHg}$, or lung infiltrates $>50 \%$ (13). Written consent was obtained from all patients or close relatives upon admission. We analysed the data of 6831 patients who were admitted or transferred from other hospitals and health centres to the referral hospitals. All hospitalized COVID-19 cases were either confirmed by positive RT-PCR, unconfirmed by negative RT-PCR, or were untested. Detailed analysis was limited to 5055 patients who were tested with RT-PCR. The study was approved by the Ethics Committee of IUMS.

\section{Data collection}

Data gathering forms were completed first by nurses upon patient admission. Our data comprised demographics, medical history of underlying comorbidities, oxygen saturation on admission, transfer to intensive care unit (ICU), mechanical ventilation, as well as clinical outcomes that consisted of death or recovery and discharge. Questions on comorbid NCDs were completed based on patients' self-report or their close relatives' answers if they were in a critical medical condition. We defined comorbidities as coexisting NCDs, including hypertension, CHD, DM, cancer, CKD and CRD. Regarding the history of these NCDs, we asked "Have you ever been diagnosed for any of these diseases by a physician?" If the answer was yes, then all medical records of the patients were reviewed by the physicians. To determine history of DM or hypertension, we added other questions such as "Do you take any hypoglycaemic or antihypertensive medication?". Attending specialized physicians completed clinical examination on admission and throughout hospitalization. Their daily notes on the clinical situation of patients were accompanied by those of registered nurses. All were reported in the medical records that were linked to the electronic health information system of the hospitals. Our clinical outcomes were death or recovery and discharge after COVID-19. Death due to COVID-19 was defined according to WHO guidelines and through medical certification in hospital (14). The data were extracted on an Excel sheet from that system to I-CORE (12). RTPCR was used to detect SARS-CoV-2 RNA according to the WHO protocol from samples of throat swabs (15). Samples were sent to 2 designated laboratories related to the provincial health centre. All routine and other necessary laboratory tests were done for patients. I-CORE Webbased software was developed to retrieve, save, manage and integrate collected patients' data from admission and the health information system of referral hospitals. If there were missing data, nurses went back to patients' medical records to fill the gaps.

\section{Statistical analysis}

Continuous variables including age were presented as means and standard deviation and were compared by Mann-Whitney $U$ test. Categorical variables, frequency and percentage of patients with oxygen saturation $<93 \%$, mechanical ventilation needed, ICU transfer, and clinical outcome based on sex and different RT-PCR results were compared by $\chi^{2}$ test. A logistic regression model was used to determine the association of comorbidity with death as well as clinical characteristics including oxygen saturation, need for mechanical ventilation and ICU admission. Odds ratio (OR) and 95\% confidence interval (CI) were reported. Age as continuous variable, sex, oxygen saturation, mechanical ventilation, ICU, and NCDs were adjusted in the logistic regression model. $P<0.05$ was considered statistically significant. Statistical analyses were done using Stata version 14.

\section{Results}

\section{Demographics and clinical characteristics}

From 17 February to 6 April 2020, 6831 patients with a WHO definition of COVID- 19 were admitted to referral hospitals in Isfahan Province; among whom, 5055 had RT-PCR results, with a higher frequency of male compared to female patients (54.9\% vs $45.1 \%$ ). Table 1 presents the demographic and clinical characteristics of these patients. Mean age was 56.1 (20.5) years for RT-PCR-positive patients compared to 59.3 (17.3) years for negative patients. Older age distribution was significantly higher in positive patients. Although low oxygen saturation and ICU admission were significantly higher in the positive 


\begin{tabular}{|c|c|c|c|}
\hline Characteristics & $\begin{array}{c}\text { RT-PCR negative } \\
n(\%)\end{array}$ & $\begin{array}{c}\text { RT-PCR positive } \\
n(\%)\end{array}$ & $\mathbf{P}$ \\
\hline \multicolumn{4}{|l|}{ Sex } \\
\hline Male & $1598(54.4)$ & $1175(55.5)$ & \multirow[t]{2}{*}{0.415} \\
\hline Female & $1,341(45.6)$ & $941(44.5)$ & \\
\hline \multicolumn{4}{|l|}{ Age } \\
\hline Mean (SD), yr & $56.1(20.5)$ & $59.3(17.3)$ & $<0.0001^{a}$ \\
\hline \multicolumn{4}{|l|}{ Age groups $n(\%)$} \\
\hline$<1$ & $11(0.37)$ & $3(0.14)$ & \multirow[t]{7}{*}{$<0.0001^{b}$} \\
\hline $1-15$ & $80(2.7)$ & $8(0.38)$ & \\
\hline $16-30$ & $252(8.6)$ & $92(4.4)$ & \\
\hline $31-45$ & $544(18.5)$ & $387(18.3)$ & \\
\hline $46-60$ & $745(25.4)$ & $557(26.3)$ & \\
\hline $61-75$ & $724(24.6)$ & $676(32.0)$ & \\
\hline 75 & $583(19.8)$ & $393(18.6)$ & \\
\hline $\mathrm{SO}_{2}<93 \% n(\%)$ & $1679(57.1)$ & $1285(60.7)$ & $0.01^{b}$ \\
\hline Mechanical ventilation, $n(\%)$ & $194(6.6)$ & $89(4.2)$ & $<0.0001^{\mathrm{b}}$ \\
\hline ICU admission, $n(\%)$ & $342(11.6)$ & $281(13.3)$ & $0.045^{\mathrm{b}}$ \\
\hline \multicolumn{4}{|l|}{ Clinical outcome, $n(\%)$} \\
\hline Deceased, $n(\%)$ & $311(10.6)$ & $266(12.6)$ & $0.028^{b}$ \\
\hline Mean (SD) age, yr & $67.9(18.8)$ & $72.0(14.5)$ & $0.004^{\mathrm{a}}$ \\
\hline Recovered/discharge, $n$ (\%) & $1767(60.1)$ & $1173(55.4)$ & $0.001^{\mathrm{b}}$ \\
\hline Mean (SD) age, yr & $53.7(20.3)$ & $56.5(16.6)$ & $<0.0001^{\mathrm{a}}$ \\
\hline Hospitalized, $\mathbf{n}(\%)$ & $861(29.3)$ & $677(32.0)$ & $0.040^{\mathrm{b}}$ \\
\hline Mean (SD) age, yr & $56.6(20.0)$ & $59.2(17.4)$ & $0.007^{\mathrm{a}}$ \\
\hline \multicolumn{4}{|l|}{ NCD } \\
\hline $\mathrm{DM}$ & $402(13.7)$ & $362(17.1)$ & $0.001^{b}$ \\
\hline Hypertension & $200(6.8)$ & $206(9.7)$ & $<0.0001^{b}$ \\
\hline CHD & 447 (16.2) & $323(15.3)$ & 0.848 \\
\hline CRD & $182(6.2)$ & $89(4.2)$ & $0.002^{\mathrm{b}}$ \\
\hline Cancer & $113(3.8)$ & $44(2.1)$ & $<0.0001^{b}$ \\
\hline CKD & $113(3.8)$ & $63(3.0)$ & 0.242 \\
\hline Any $\mathrm{NCD}^{\mathrm{c}}$ & $1043(35.5)$ & $736(34.8)$ & 0.604 \\
\hline
\end{tabular}

${ }^{a}$ Independent test and ${ }^{b} \chi 2$ test considered significant at $\mathrm{P}<0.05$.

'Presence of at least 1 of 6 studied NCDs.

$C H D=$ coronary heart disease $C K D=$ chronic kidney disease $; C R D=$ chronic respiratory disease; $D M=$ diabetes mellitus; ICU = intensive care unit; IQR = interquartile range; $\mathrm{NCD}=$ noncommunicable disease; $\mathrm{RT}-\mathrm{PCR}=$ reverse transcription polymerase chain reaction; $\mathrm{SD}=$ standard deviation; $\mathrm{SO} 2=$ oxygen saturation .

group, mechanical ventilation was used more in the negative group. In the positive group, $12.6 \%$ of patients died compared with $10.6 \%$ in the negative group, which was a significant difference. However, the mortality rate did not differ significantly between male $(11.8 \%)$ and female (11\%) patients. DM and hypertension were significantly higher in the positive patients, while cancer and CRD were higher in the negative group. Other NCDs, including CHD and CKD, were present in both groups without significant differences.

Among hospitalized patients with COVID-19 irrespective of RT-PCR results, 2940 cases were discharged and 577 died. Table 2 shows the association of demographic characteristics and comorbidity with death in patients hospitalized with COVID-19 with positive and negative
RT-PCR results. Death rate in patients aged $\geq 70$ years was significantly higher, while the difference between deceased and discharged patients according to sex was not significant. The frequency of comorbidities including DM, CHD, CRD and cancer as well as patients with at least 1 comorbidity was higher in deceased cases than in survivors. Unadjusted analysis indicated a significant association between age $\geq 70$ years, DM, CHD, CRD, cancer, presence of at least 1 of 6 studied NCDs and death rate. After age and sex adjustment, we found a significant association between CRD, cancer and presence of at least 1 of 6 studied NCDs and death. However, following adjustment for all potential confounders, only the relationship between age and cancer with death remained significant. 

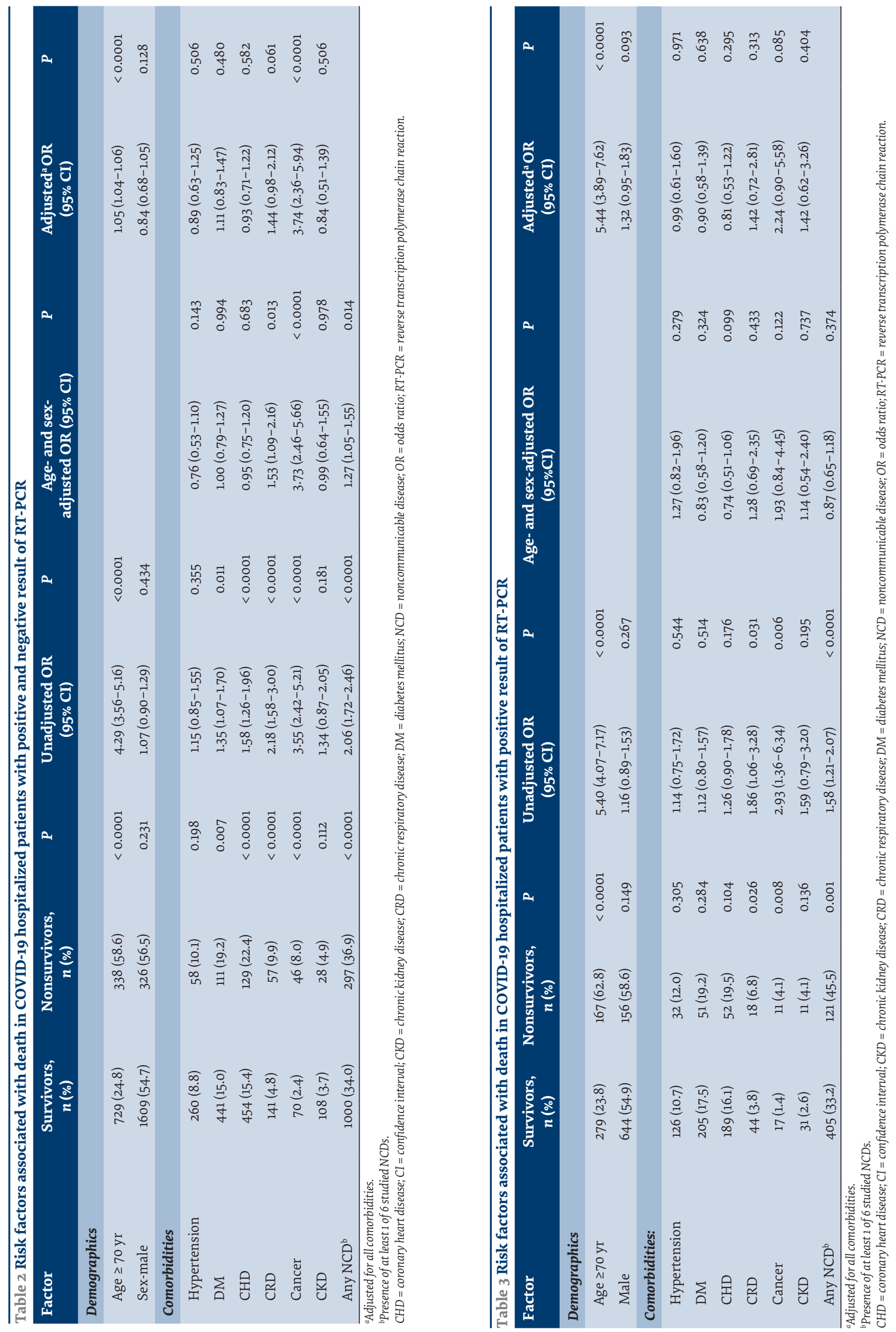
Out of the 1439 RT-PCR-positive patients, 266 died and 1173 survived and were discharged. Table 3 presents the association of demographics and NCDs with death only in patients with positive RT-PCR results. The mortality rate was higher in patients aged $\geq 70$ years, presence of $C R D$, cancer and at least 1 of 6 studied comorbidities. Unadjusted analysis showed that age $\geq 70$ years, and presence of $C R D$, cancer and any NCD were significantly associated with death. There was no significant association between any NCD and death in the age- and sex-adjusted model. Only age $\geq$ 70 years remained significant after adjustment for all clinical parameters.

Table 4 shows a significant association between CRD and cancer and greater need for mechanical ventilation, but hypertension was inversely related to mechanical ventilation requirement. After age and sex adjustment, this association was decreased for CRD and cancer and disappeared for hypertension. Hypertension, DM, CHD, CRD and CKD had a significant relationship with lower oxygen saturation and ICU admission. After age and sex adjustment, these relationships disappeared between CKD and low oxygen saturation but were significant for hypertension, DM, CHD and CRD. The association of ICU admission with hypertension and CRD disappeared after age and sex adjustment, but remained significant for DM, CHD and CKD.

\section{Discussion}

The current study presents an overview of comorbid NCDs and prognosis in hospitalized patients with COVID-19 in Isfahan Province, Islamic Republic of Iran, as well as the association between clinical course and NCDs. This study included patients hospitalized according to WHO criteria but with RT-PCR irrespective of the results, while excluding hospitalized patients without testing. This was a departure from other studies in which cases fitting a clinical definition were included. Our main findings were: the mean age of patients with a positive RT-PCR was significantly higher than that of patients with negative RT-PCR, and older patients had a higher risk of mortality compared with younger patients. This was similar to studies in China, the United Kingdom of Great Brit-

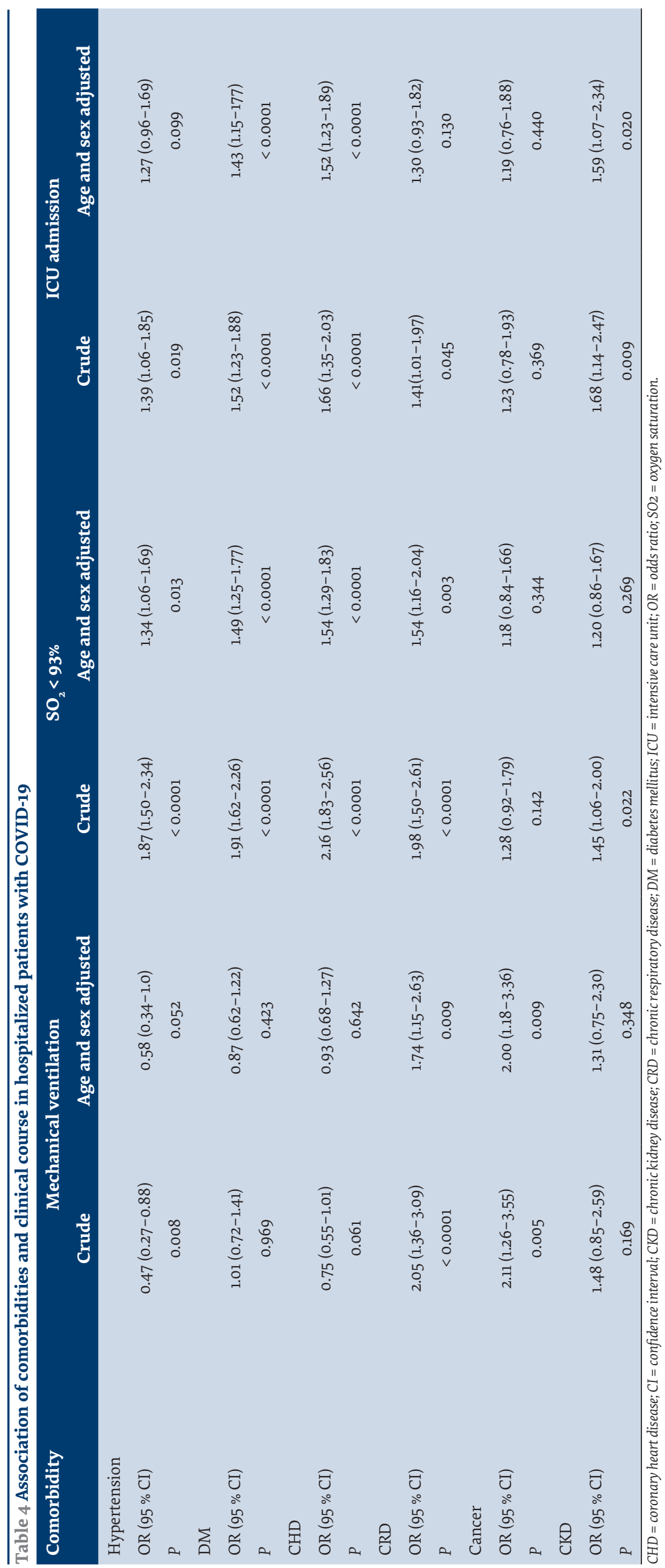


ain and Northern Ireland, United States of America (USA) and Republic of Korea $(9,15-17)$. Male predominance observed in this study was similar to that in other published studies on COVID-19 $(9,15-17)$. Patients aged $\geq 70$ years had a higher mortality risk and this was similar to that reported in the USA (16). In contrast to global findings, mortality rate showed no significant difference between men and women (4), although hospitalization was higher in men.

While low oxygen saturation and ICU admission rates were significantly more frequent in patients with positive RT-PCR tests, mechanical ventilation was significantly higher in patients with negative results. These results may be explained by limited validity of our RT-PCR tests. Similar results were reported in other countries, such as 30-50\% false-negative rate in China and $>5 \%$ in the USA $(18,19)$. Multiple factors can play a role in such results, like the method of obtaining samples, method of transfer, technical issues and nonvalid kits.

One of our main findings was that CHD and DM were the most common NCDs in our patients with positive or negative RT-PCR tests. This is similar to other studies $(5,9,15-17,20,21)$. Similarly, studies in China and Italy showed that the most prevalent underlying condition was hypertension $(9,21,22)$. Other comorbidities reported in our study were cancer, CKD and CRD, which were similar to other studies $(5,9,10,15-17,20-23)$. Differences between our and other studies may be due to methodology as our data on the presence of NCDs were self-reported which may have resulted in underestimation.

The presence of any of the 6 studied NCDs increased mortality by more than twice in patients with positive or negative RT-PCR results and by $58 \%$ only in patients with positive RT-PCR results. Unadjusted analysis showed that DM, CHD, CRD and cancer were significant risk factors for death in all COVID-19 patients with negative and positive RT-PCR results; however, in our full adjustment analysis, only cancer showed a significant association with death. Among patients with positive RT-PCR results, CRD and cancer were significantly associated with death, which vanished after adjustment for confounders including clinical course. A strong association between NCDs and some clinical characteristics may affect COVID-19 prognosis and cause disappearance of the association of NCDs and COVID-19 death after adjustment for clinical factors. CRD and cancer were associated with increased frequency of mechanical ventilation by 1.74 and 2 times, respectively. Hypertension, DM, CHD and CRD had 34$54 \%$ greater occurrence of oxygen saturation $<93 \%$. DM, CHD and CKD were associated with increased frequency of ICU transfer by $43 \%, 52 \%$ and $59 \%$, respectively . Similarly, previous studies have shown the predictive effects of underlying NCDs in increasing the number of patients with clinical features such as ICU transfer, oxygen saturation and mechanical ventilation $(24,25)$.

A meta-analysis of 40 studies on 18012 COVID-19 patients showed that DM, hypertension and CVD were important risk factors for COVID-19 mortality (26). However, most studies did not adjust all the confounders that we did in our study. A study in Italy showed that hypertension was not an independent predictor of COVID-19 outcomes (27). Consistent with the current study, cancer comorbidity was associated with more adverse COVID-19 outcomes (28). In patients with $\mathrm{DM}$, immune dysfunction, proinflammatory and prothrombotic hypercoagulable state are related to COVID-19 mortality (29).

To the best of our knowledge, this is the first report from the Islamic Republic of Iran on the association of some clinical characteristics of COVID-19 with comorbid NCDs that worsen the prognosis of hospitalized patients. The study had some limitations. Firstly, comorbidities were self-reported by patients or their close relatives which may have led to under-reporting the frequency due to lack of awareness. Secondly, the limited validity of RT-PCR testing may have underestimated the number of confirmed cases of COVID-19.

\section{Conclusion}

We conclude that COVID-19 infection and death were associated with age and male sex in patients hospitalized with COVID-19 in the Islamic Republic of Iran. DM, CHD and hypertension were the most prevalent underlying comorbidities. The presence of at least 1 of the studied NCDs increased mortality in patients with positive or negative RT-PCR results. However, none of the NCDs was associated significantly with death after adjustment of all confounders in patients with positive RT-PCR results. This analysis and other reports from I-CORE can be helpful for policy-makers to make proper decisions on referring patients, facilities, management and treatment of high-risk patients.

\section{Acknowledgment}

We express our special thanks to all physicians, nurses and other staff who were frontline healthcare providers in our COVID-19 referral hospitals. We also thank all the patients and their families who provided consent to use their data in our analysis. The efforts of all staff of health centres and laboratories who test COVID-19 in Isfahan Province is appreciated.

Funding: None.

Competing interests: None declared. 


\section{Maladies non transmissibles, évolution clinique et pronostic de COVID-19 : résultats basés sur le registre I-CORE}

\section{Résumé}

Contexte : Il n'existe pas de données sur le lien entre comorbidités et évolution clinique chez les patients iraniens atteints de COVID-19.

Objectifs : Déterminer les maladies non transmissibles (MNT), les caractéristiques cliniques et le pronostic des patients hospitalisés pour COVID-19 à Ispahan (République islamique d'Iran).

Méthodes: La présente étude observationnelle rétrospective multicentrique a été réalisée sur tous les patients hospitalisés pour COVID-19 à Ispahan entre le 17 février et le 6 avril 2020. Nous avons recruté 5055 patients. Des données sur l'évolution clinique et les comorbidités avec des maladies non transmissibles telles que l'hypertension, les coronaropathies, le diabète sucré, le cancer, la maladie rénale chronique et les maladies respiratoires chroniques ont été recueillies. Des analyses statistiques ont été effectuées à l'aide de tests de Mann-Whitney $(\mathrm{U}), \chi^{2}$ et de régression logistique avec le logiciel Stata version 14.

Résultats: Le diabète sucré et l'hypertension constituaient les comorbidités les plus prévalentes chez les patients présentant une réaction en chaîne par polymérase après transcription inverse (RT-PCR) positive et négative. L'odds ratio (intervalle de confiance à $95 \%$ ) des facteurs associés à la mortalité était significatif pour le diabète sucré $[1,35(1,07-1,70)]$, les coronaropathies [1,58 (1,26-1,96)], les maladies respiratoires chroniques [2,18 (1,58-3,0)] et le cancer $[3,55(2,42-5,21)]$. Ces résultats restaient significatifs pour le cancer après ajustement en fonction de l'âge, du sexe et des facteurs cliniques. Chez les patients dont les tests RT-PCR étaient positifs, la mortalité était significativement associée aux maladies respiratoires chroniques et au cancer, tandis que cette association disparaissait après ajustement en fonction de tous les facteurs de confusion possibles. Il existait un lien important entre les maladies non transmissibles et la survenue plus fréquente d'une faible saturation en oxygène, d'un besoin en ventilation mécanique et d'une admission en unité de soins intensifs après ajustement en fonction de l'âge et du sexe.

Conclusion : La présence de maladies non transmissibles à elle seule n'a pas augmenté la mortalité chez les patients atteints de COVID-19, après ajustement en fonction de tous les facteurs de confusion possibles, y compris les facteurs cliniques.

$$
\text { الأمر اض غير السارية، والمسار السريري، و التنبؤ بسيْر كوفيد-19 : نتائج مستندة لسجل كوفيد-19 }
$$

شقايق جافانمارد، نوشين محمدي-فرد، مريم ناصريان، جولناز واسيغي، كمال حيدري، بهروز كليداري، طاهرة تشانجيز، نزال صر افزايجان

$$
\text { الخلفية: لا تتوافر بيانات عن الارتباط بين المسار السريري والأمراض المُصاحبة في المرضى الإيرانيين المصابين بكوفيد-19. }
$$

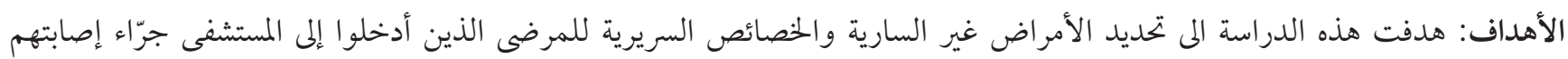

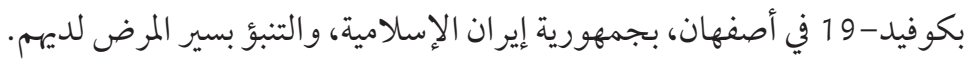

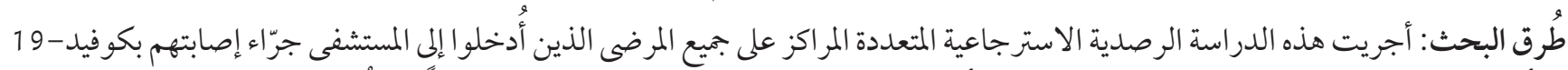

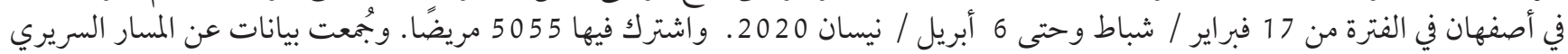

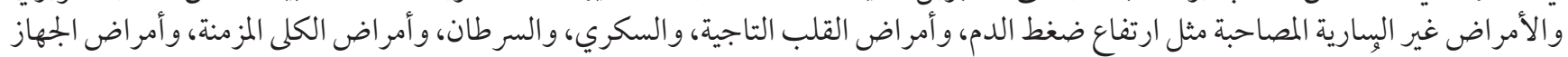

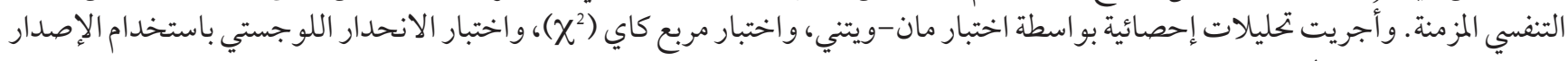

$$
14 \text { من برنامج Stata الحاسوبي. }
$$

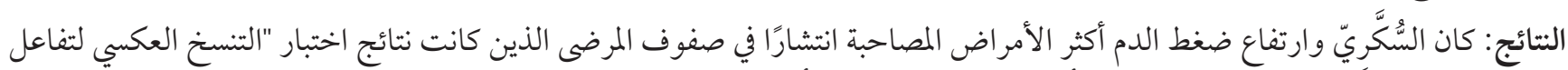

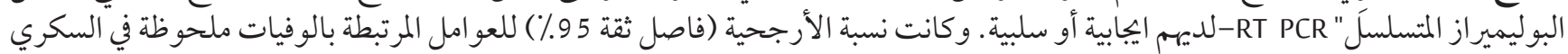

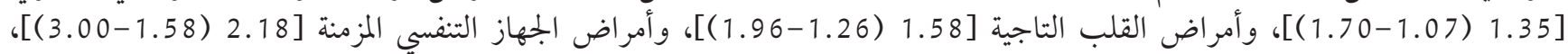

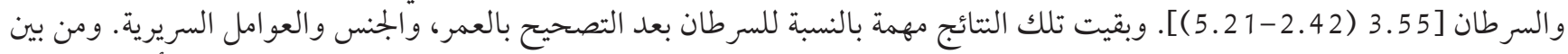

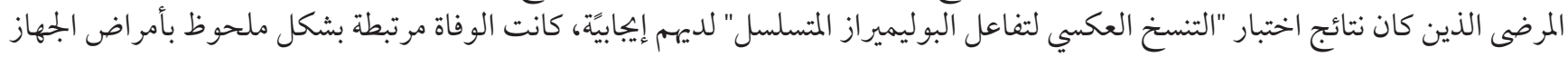

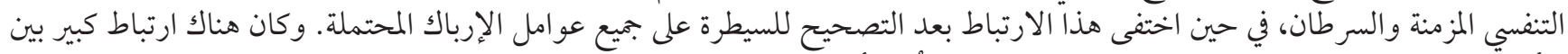

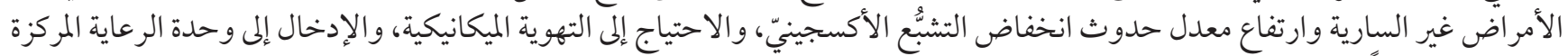
بعد التصحيح وفقًا للعمر والجنس.

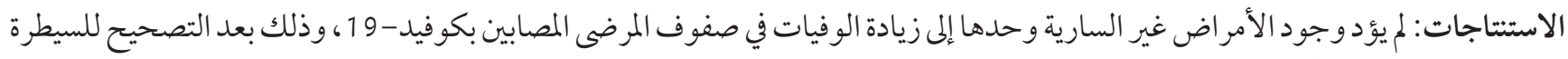

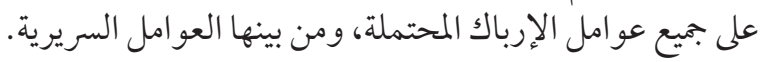




\section{References}

1. Report of the WHO-China joint mission on coronavirus disease 2019 (COVID-19). Geneva: World Health Organization; 2020 (https://www.who.int/publications/i/item/report-of-the-who-china-joint-mission-on-coronavirus-disease-2019-(covid-19), acp cessed 6 July 2021).

2. Zheng J. SARS-CoV-2: an emerging coronavirus that causes a global threat. Int J Biol Sci. 2020 Mar 15;16(10):1678-85. https://doi. org/10.7150/ijbs.45053 PMID:32226285

3. WHO Director-General's opening remarks at the media briefing on COVID-19. 11 March 2020 [website]. Geneva: World Health Organization; 2020 (https://www.who.int/director-general/speeches/detail/who-director-general-s-opening-remarks-at-the-media-briefing-on-covid-19---11-march-2020).

4. COVID-19 coronavirus pandemic [website] (https://www.worldometers.info/coronavirus/, accessed 6 July 2021).

5. Xu X-W, Wu X-X, Jiang X-G, Xu K-J, Ying L-J, Ma C-L, et al. Clinical findings in a group of patients infected with the 2019 novel coronavirus (SARS-Cov-2) outside of Wuhan, China: retrospective case series. BMJ. 2020 Feb 19;368:m606. https://doi.org/10.1136/ bmj.m606 PMID:32075786

6. Benziger CP, Roth GA, Moran AE. The Global Burden of Disease Study and the preventable burden of NCD. Glob Heart. 2016 Dec;11(4):393-7. https://doi.org/10.1016/j.gheart.2016.10.024 PMID:27938824

7. NCD Countdown 2030 collaborators: worldwide trends in non-communicable disease mortality and progress towards Sustainable Development Goal target 3.4. Lancet. 2018 Sep 22;392(10152):1072-88. https://doi.org/10.1016/So140-6736(18)31992-5 PMID:30264707

8. Khosravi Shadmani F, Farzadfar F, Larijani B, Mirzaei M, Haghdoost AA. Trend and projection of mortality rate due to non-communicable diseases in Iran: a modeling study. PLoS One. 2019 Feb 14;14(2):e0211622. https://doi.org/10.1371/journal.pone.0211622 PMID:30763320

9. Chen N, Zhou M, Dong X, Qu J, Gong F, Han Y, et al. Epidemiological and clinical characteristics of 99 cases of 2019 novel coronavirus pneumonia in Wuhan, China: a descriptive study. Lancet. 2020 Feb 15;395(10223):P507-13. https://doi.org/10.1016/So1406736(20)30211-7

10. Wang D, Hu B, Hu C, Zhu F, Liu X, Zhang J, et al. Clinical characteristics of 138 hospitalized patients with 2019 novel coronavirus-infected pneumonia in Wuhan, China. JAMA. 2020 Mar 17; 323(11):1061-9. https://doi.org/10.1001/jama.2020.1585 PMID:32031570

11. Kluge HHP, Wickramasinghe K, Rippin HL, Mendes R, Peters DH, Kontsevaya A, et al. Prevention and control of non-communicable diseases in the COVID-19 response. Lancet. 2020 May 30;395(10238):1678-80. https://doi.org/10.1016/So140-6736(20)31067 PMID:32401713

12. Javanmard S, Nasirian M, Ataei B, Vaseghi G, Vaezi A, Changiz T. Isfahan COvid-19 REgistry (I-CORE): Design and methodology. J Res Med Sci. 2020 Mar 30;25:32. https://doi.org/10.4103/jrms.JRMS_271_20 PMID:32582338

13. Clinical management of severe acute respiratory infection when novel coronavirus (2019-nCoV) infection is suspected: interim guidance, 28 January 2020. Geneva: World Health Organization; 2020 (https://apps.who.int/iris/handle/10665/330893, accessed 6 July 2021).

14. International guidelines for certification and classification (coding) of covid-19 as cause of death based on ICD international statistical classification of diseases. Geneva: World Health Organization (https://www.who.int/classifications/icd/Guidelines_ Cause_of_Death_COVID-19.pdf?ua=1, accessed 1 April 2021).

15. Docherty AB, Harrison EM, Green CA, Hardwick HE, Pius R, Norman L, et al. Features of 20133 UK patients in hospital with covid-19 using the ISARIC WHO clinical characterisation protocol: prospective observational cohort study. BMJ. 2020 May 22;369:m1985. https://doi.org/10.1136/bmj.m1985 PMID:32444460

16. Petrilli CM, Jones SA, Yang J, Rajagopalan H, Luke O'Donnell, et al. Factors associated with hospital admission and critical illness among 5279 people with coronavirus disease 2019 in New York City: prospective cohort study. BMJ. 2020;369:m1966. https://doi.org/10.1136/bmj.m1966

17. Report on the Epidemiological Features of Coronavirus Disease 2019 (COVID-19) Outbreak in the Republic of Korea from January 19 to March 2, 2020. J Korean Med Sci. 2020 Mar 16;35(10):el12. https://doi.org/10.3346/jkms.2020.35.e112 PMID:32174069

18. Pan Y, Long L, Zhang D, Yan T, Cui S, Yang P, et al. Potential false-negative nucleic acid testing results for severe acute respiratory syndrome coronavirus 2 from thermal inactivation of samples with low viral loads. Clin Chem. 2020 Jun 1;66(6):794-801. https://doi.org/10.1093/clinchem/hvaao91 PMID:32246822

19. West CP, Montori VM, Sampathkuma P. COVID-19 testing: the threat of false-negative results. Mayo Clin Proc. 2020 Jun;95(6):1127-9. https://doi.org/10.1016/j.mayocp.2020.04.004 PMID:32376102

20. Huang C, Wang Y, Li X, Ren L, Zhao J, Hu Y, et al. Clinical features of patients infected with 2019 novel coronavirus in Wuhan, China. Lancet. 2020 Feb 15;395(10223):497-506. https://doi.org/10.1016/So140-6736(20)30183-5

21. Guan WJ, Liang WH, Zhao Y, Liang HR, Chen ZS, Li YM, et al. Comorbidity and its impact on 1590 patients with COVID-19 in China: a nationwide analysis. Eur Respir J. 2020 May 14;55(5):2000547. https://doi.org/10.1183/13993003.00547-2020 PMID:32217650

22. Liu K, Fang YY, Deng Y, Liu W, Wang MF, Ma JP, et al. Clinical characteristics of novel coronavirus cases in tertiary hospitals in Hubei Province. Chin Med J (Engl). 2020 May 5;133(9):1025-31. https://doi.org/10.1097/CM9.0000000000000744 PMID:32044814 
23. Zhou F, Yu T, Du R, Fan G, Liu Y, Liu Z, et al. Clinical course and risk factors for mortality of adult inpatients with COVID-19 in Wuhan, China: a retrospective cohort study. Lancet. 2020 Mar 28;395(10229):1054-62. https://doi.org/10.1016/So1406736(20)30566-3 PMID:32171076

24. Ioannou GN, Locke E, Green P, Berry K, O'Hare AM, Shah JA, et al. Risk factors for hospitalization, mechanical ventilation, or death among 10131 US veterans with SARS-CoV-2 infection. JAMA Netw Open. 2020 Sep 1;3(9):e2022310. https://doi.org/10.1001/ jamanetworkopen.2020.22310 PMID:32965502

25. Ahlström B, Frithiof R, Hultström M, Larsson IM, Strandberg G, Lipcsey M. The swedish covid-19 intensive care cohort: risk factors of ICU admission and ICU mortality. Acta Anaesthesiol Scand. 2021 Jan 12. https://doi.org/10.1111/aas.13781 PMID:33438198

26. de Almeida-Pititto B, Dualib PM, Zajdenverg L, Dantas JR, de Souza FD, Rodacki M, et al. Severity and mortality of COVID 19 in patients with diabetes, hypertension and cardiovascular disease: a meta-analysis. Diabetol Metab Syndr. 2020 Aug 31;12:75. https://doi.org/10.1186/s13098-020-00586-4 PMID:32874207

27. Iccarino G, Grassi G, Borghi C, Ferri C, Salvetti M, Vole M, et al. Age and multimorbidity predict death among COVID-19 patients. Results of the SARS-RAS Study of the Italian Society of Hypertension. Hypertension. 2020 Aug;76(2):366-72. https://doi. org/10.1161/HYPERTENSIONAHA.120.15324 PMID:32564693

28. Jee J, Foote MB, Lumish M, Stonestrom AJ, Wills B, Narendra V, et al. Chemotherapy and COVID-19 outcomes in patients with cancer. J Clin Oncol. 2020 Oct 20;38(30):3538-46. https://doi.org/10.1200/JCO.20.01307 PMID:32795225

29. Morra ME, Van Thanh L, Kamel MG, Ghazy AA, Altibi AMA, Dat LM. Clinical outcomes of current medical approaches for Middle East respiratory syndrome: a systematic review and meta-analysis. Rev Med Virol. 2018 May;28(3):e1977. https://doi. org/10.1002/rmv.1977 PMID:29664167 